\title{
EDitorial EDitorial
}

É com imenso prazer que apresentamos ao público o número 22 da Revista Temporalis. Este número intenciona comemorar os 65 anos de Abess/ Abepss e 15 anos da aprovação, pela categoria, das Diretrizes Gerais para o curso de Serviço Social no Brasil. Destes 65 anos de existência da entidade, 52 anos se constituíram como Associação Brasileira de Ensino em Serviço Social; os outros 13 anos como Associação Brasileira de Ensino e Pesquisa em Serviço Social.

Que mudanças ocorreram? Dentre as muitas atividades e projetos empreendidos, destacamos o investimento em pesquisa e na produção do conhecimento crítico como vetor que orienta a entidade - o que modifica radicalmente suas finalidades. A partir daí, coerente com o projeto de formação profissional e com as Diretrizes Gerais para o Curso de Serviço Social, aprovados na Gestão da Professora Marieta Koike, ganha fortalecimento a indissociabilidade entre ensino, pesquisa e extensão, e a necessária relação entre Graduação e Pós-graduação.

Dentre nossas conquistas, podemos destacar o fato de que nossa entidade acadêmico-científica é a única do país que trata tanto do ensino de graduação quanto do de pós-graduação entendendo a pesquisa como um elemento que pode fortalecer a relação entre essas duas instâncias da formação profissional.

Como um presente de aniversário, esse número vem nos brindar, além da qualidade dos textos apresentados, com a tão almejada regularização deste periódico. Regularização conquistada com a contribuição das gestões que nos antecederam, do Comitê Editorial atual e, especialmente pelo esforço e dedicação das queridas companheiras, professoras doutoras Jussara Maria Rosa Mendes (UFRGS) e Maria Lúcia Teixeira Garcia (Ufes), a quem fazemos um agradecimento especial. 
Como parte destas comemorações, este número da Revista Temporalis apresenta, artigos de temas livres que salientam a contribuição da Abepss ao debate teórico-político do Serviço Social, no que se refere à formação pós-graduada e à pesquisa, bem como, temas candentes para a formação e exercício profissional do Assistente Social, hoje. Como inovação, traz uma seção especial contendo a historiografia da Abepss, contada a partir da exposição de alguns de seus ex-presidentes. Estes contextualizam sua gestão, as lutas, as conquistas e os desafios postos para a Abepss naquele momento histórico. Na concepção deste número da revista, priorizamos o depoimento das gestões que sucederam a aprovação das Diretrizes Gerais para os Cursos de Serviço Social, tendo em vista, a comemoração dos seus 15 anos, sem deixar de reconhecer, a contribuição das gestões anteriores para esse processo. Nesta historiografia é fundamental registrar a importante interlocução desta entidade com o conjunto Conselho Federal de Serviço Social/Conselhos Regionais de Serviço Social e Executiva Nacional de Estudantes de Serviço Social (CFESS/Cress e Enesso), o que vem sendo feito respeitando-se a autonomia das mesmas.

Evidentemente, nem todos/as ex-presidentes puderam enviar sua contribuição. Não obstante, assinalamos aqui - sem pretensão de esgotar a riqueza destas gestões - seus esforços na direção do amadurecimento de nosso projeto de formação profissional como uma das expressões de nosso Projeto Ético Político nestes 15 anos, dentre os quais: a elaboração, o debate nacional e a aprovação do Documento Diretrizes Gerais para o Curso de Serviço Social; a construção de um novo estatuto com a criação de uma entidade única, transformando a Abess em Abepss e incorporando o Cedepss; a elaboração e divulgação de documento sobre a trajetória da pós-graduação em Serviço Social no país, divulgado no VI Enpess; luta pela aprovação das diretrizes curriculares no âmbito do Conselho Nacional de Educação/Ministério da Educação (CNE/MEC) e sua implantação nas UFAs, no contexto da contrarreforma do ensino superior realizada pelo Governo FHC; criação da Revista Temporalis; realização do I e ll Curso de Especialização a Distância para Assistentes Sociais em convênio com o CFESS; trabalho de assessoria às unidades de ensino para enraizar o projeto de formação profissional; interferência nos parâmetros e processos de avaliação institucional dos cursos de Serviço Social; Pesquisa Avaliativa da Implementação das Diretrizes Curriculares do Curso de Serviço Social; eventos nacionais e regionais para divulgação dos resultados da pesquisa; distribuição para as unidades de formação acadêmica de material digital com o resultado da pesquisa; promoção de 
debates sobre o exame de proficiência para Assistentes Sociais; conquista e inauguração da nova sede em Brasília (Universidade de Brasília/UnB); campanha de filiação de sócios individuais e institucionais; elaboração em conjunto com CFESS e Enesso do Plano de Lutas em Defesa do TrabaIho e da Formação e Contra a Precarização do Ensino Superior; elaboração, aprovação e implementação da Política Nacional de Estágio (PNE); criação e implementação dos Grupos Temáticos de Pesquisa (GTPs).

Segue listagem com todas as gestões da ABEPSS de 1946 até 2011. A elas nossa homenagem e a todos que vêm participando de forma direta e indireta com esta entidade, em especial, nossa deferência às Professoras Nobuco Kameyama e Nadir Kfouri, falecidas recentemente, pela contribuição efetiva ao Serviço Social Brasileiro.

Odila Cintra Fereira (in memoriam) (PUC/SP)

Margarida Maria Souto Filgueira (UFRN)

Marina Colombo de Bartolo (in memoriam) (PUC/SP)

Maria Amália Soares Arozo (UFRJ)

Maria das Dores Costa (UFRN)

Raquel Mäder Gonçalves (Universidade Católica do Paraná)

Cândida Maria Fontes de Santana (UFS)

Josefa Batista Lopes (UFMA)

Maria Carmelita Yasbek (PUC/SP)

Eugênia Célia Raizer (Ufes)

Justina Iva de Araújo Silva (UFRN)

Consuelo Quiroga (PUC/MG)

Lidia Maria Monteiro Rodrigues da Silva (UEL)

Maria Marieta dos Santos Koike (UFPE)

Reinaldo Nobre Pontes (Unama)

A partir de 1998 passa a denominar Abepss

Ivanete Boschetti (UNB)

Maria Aparecida Tardin Cassab (UFF/UFJF)

Jussara Mendes (PUC-RS)

Ana Elizabete Mota (UFPE)

Marina Maciel Abreu (UFMA)

Elaine Rossetti Behring (UERJ) 